\title{
Article
}

\section{Career Development among American Biomedical Postdocs}

\author{
Kenneth D. Gibbs, Jr., ${ }^{* \ddagger \ddagger}$ John McGready, $\$$ and Kimberly Griffin ${ }^{\ddagger}$
}

\begin{abstract}
*Cancer Prevention Fellowship Program, Division of Cancer Prevention, and 'Science of Research and Technology Branch, Behavioral Research Program, Division of Cancer Control and Population Sciences, National Cancer Institute, Bethesda, MD 20850; § Department of Biostatistics, Johns Hopkins Bloomberg School of Public Health, Baltimore, MD 21205; "Department of Counseling, Higher Education, and Special Education, University of Maryland, College Park, MD 20742
\end{abstract}

Submitted March 26, 2015; Revised August 11, 2015; Accepted August 18, 2015

Monitoring Editor: Graham F. Hatfull

\begin{abstract}
Recent biomedical workforce policy efforts have centered on enhancing career preparation for trainees, and increasing diversity in the research workforce. Postdoctoral scientists, or postdocs, are among those most directly impacted by such initiatives, yet their career development remains understudied. This study reports results from a 2012 national survey of 1002 American biomedical postdocs. On average, postdocs reported increased knowledge about career options but lower clarity about their career goals relative to PhD entry. The majority of postdocs were offered structured career development at their postdoctoral institutions, but less than one-third received this from their graduate departments. Postdocs from all social backgrounds reported significant declines in interest in faculty careers at research-intensive universities and increased interest in nonresearch careers; however, there were differences in the magnitude and period of training during which these changes occurred across gender and race/ethnicity. Group differences in interest in faculty careers were explained by career interest differences formed during graduate school but not by differences in research productivity, research self-efficacy, or advisor relationships. These findings point to the need for enhanced career development earlier in the training process, and interventions sensitive to distinctive patterns of interest development across social identity groups.
\end{abstract}

\section{INTRODUCTION}

The career training and prospects of biomedical science PhDs have commanded significant attention from the science policy community (Alberts et al., 2014; Daniels, 2015), the popular press (Harris, 2014; Weissman, 2014), and trainees themselves (McDowell et al., 2014; Polka and Krukenberg,

CBE Life Sci Educ December 1, 2015 14:ar44

DOI:10.1187/cbe.15-03-0075

‡These authors contributed equally to this work.

Address correspondence to: Kenneth D. Gibbs (kgibbsjr@gmail .com, kenneth.gibbs@nih.gov).

(C) 2015 K. D. Gibbs et al. CBE—Life Sciences Education (c) 2015 The American Society for Cell Biology. This article is distributed by The American Society for Cell Biology under license from the author(s). It is available to the public under an Attribution-Noncommercial-Share Alike 3.0 Unported Creative Commons License (http:/ / creativecommons.org/licenses/by-nc-sa/3.0).

"ASCB ${ }^{\circledR}$ " and "The American Society for Cell Biology" are registered trademarks of The American Society for Cell Biology.
2014). Increased attention has been focused on the need to adjust the career development biomedical PhDs receive, so they are better prepared for a career landscape in which only $11-25 \%$ eventually move on to faculty positions (Yamamoto, 2014). Alongside these efforts, a focus remains on enhancing diversity in the research workforce and professoriate, as the representation of women and scientists from underrepresented minority (URM) backgrounds continues to lag their representation in the PhD pool (National Institutes of Health [NIH], 2014a; Rockey, 2014).

Postdoctoral scientists, or postdocs, are among those most directly impacted by career development initiatives. Postdocs have long been recognized as indispensable to the research enterprise, "performing a substantial portion of the nation's research in every setting" (National Research Council, 2000, p. 10). There are an estimated 60,000-100,000 postdocs in the United States-more than double the number $25 \mathrm{yr}$ ago-the majority of whom are in the life sciences (National Academy of Sciences [NAS], 2014). However, there are few systematic data on their training experiences or 
long-term outcomes (NAS, 2014). A recent NAS (2014) report concluded there is "a paucity of comprehensive data" (p. 14) about the postdoctoral system, and "neither adequate nor timely" data on postdoc "demographics, career aspirations and career outcomes" are available (p. 9).

The largest, national survey of postdoctoral scientists was Sigma Xi's Postdoc survey more than a decade ago (Davis, 2005). That study found that postdocs who reported greater amounts of structured oversight and formal training were more productive, had higher satisfaction, and were less likely to have conflicts with their advisors. Since then, there have been few peer-reviewed studies of postdocs, and those that have been published focused mainly on postdocs at single institutions (Martinez et al., 2007; Puljak and Sharif, 2009). In contrast, recent scholarship has focused on the career development of graduate students. This work has shown that, on average, students become less interested in academic careers as their training progresses and more interested in careers outside the academy and research (Fuhrmann et al., 2011; Sauermann and Roach, 2012). Further, these trends are intensified in women and scientists from URM backgrounds relative to white and Asian men (Gibbs et al., 2014). It remains unclear to what extent the career trends seen in graduate students are also reflected in the postdoctoral population, and whether there are unique patterns of postdoctoral career development.

Despite changes in the academic labor market and career preferences of trainees, it continues to be important to understand the development of interest in faculty careers, as faculty members play critical roles in shaping the nation's research agenda and training the next generation of scientists (Leggon, 2010). Increasing the representation of women and scientists from URM backgrounds has long been a priority among scientific leadership (Handelsman et al., 2005; Ferrini-Mundy, 2013), with continued underrepresentation believed to deprive the scientific enterprise of "critical contributors to [the] talent pool" (Tabak and Collins, 2011). Recent work has shown that publication record and gender can be used to predict likelihood that an investigator will progress to a faculty career (van Dijk et al., 2014); however, it is unclear how these factors influence career attainment in postdocs. As postdocs are the talent pool from which future faculty are derived, understanding the factors that influence postdoc career development is critical to effectively addressing this priority.

Extant research suggests that advisor relationships and supervision are a key component of the career development process. Work focusing on Australian postdocs suggests that supervisor relationships have great potential to impact trainee outcomes (Scaffidi and Berman, 2011). Approximately $60 \%$ of postdocs in this study had not discussed career paths outside academia with their supervisors, and participants generally wanted more social and professional networking opportunities. Lam and de Campos (2015) noted the importance of the relationship between advisor and trainee in determining continued interest in academic science (Lam and de Campos, 2015). Those with more collaborative research exchanges, with both members heavily invested in the relationship, were more likely to express a desire to stay in academia. However, those with more transactional relationships, perceived as less reciprocal, more often expressed a desire to leave and have more autonomy.
Researchers have also established strong relationships between self-efficacy and retention and success in science, particularly for younger trainees. For example, self-efficacy is one of the core constructs of social cognitive career theory (SCCT; Lent et al., 1994), suggesting that individuals confidence in their ability to complete tasks related to their fields of interest is related to the formation of career interests and persistence in educational and occupational pursuits. Self-efficacy may serve as the foundation for developing outcome expectations, career interests, and career goals in a given field (Lent et al., 2008). Science self-efficacy mediated the relationship between support services and commitment to science careers for graduate and undergraduate students of color (Chemers et al., 2011), and women who persisted in science, technology, engineering, and mathematics careers demonstrated high rates of academic and relational self-efficacy (Zelden and Pajares, 2000). Further, identifying as a scientist and sense of belonging appear central to this process, particularly for women and men of color. Sense of belonging has long been connected to student retention and success in undergraduate education (Hurtado and Carter, 1997; Hausmann et al., 2007). Again, it remains unclear whether or how these factors influence career development in postdocs.

The goal of this work is to begin to fill some of these knowledge gaps by illuminating the career development of American biomedical postdoctoral scientists. Further, it aims to integrate the sometimes distinct conversations around biomedical career development generally and enhancing gender and racial/ethnic diversity within the research workforce. Specifically, this work aims to:

1. describe the career development of postdocs, examining: a. how career interests, knowledge, and career goal clarity evolve over the course of training;

b. perceptions of access to structured career development during training;

c. perceptions of career support received from advisors and institutions;

2. understand the extent to which determinants previously linked to career attainment (e.g., research self-efficacy, productivity, training experiences) predict interest in various career pathways; and

3. examine the extent to which these patterns are overlapping and distinct by social identity (race/ethnicity, gender, and their intersection).

\section{METHODS}

\section{Data Collection and Procedures}

All work was done under the approval of the University of Maryland Institutional Review Board (IRB \#373799-5), and all respondents provided consent for participation in the study. The survey instrument and survey data-collection procedures have been previously published (Gibbs et al., 2014). Participants completed a short survey that focused on their graduate and postdoctoral training experiences, career development, and professional interests. There were a total of 1890 complete and unique responses. This analysis focuses on the respondents $(n=1002)$ who met the following criteria: 1) self-identified as a U.S. citizen or 
permanent resident, 2) held a postdoctoral position at the time of survey completion (October 2012-January 2013), and 3) completed a PhD in the biomedical or behavioral sciences (as defined by the NIH Biomedical Research Workforce Working Group Report; NIH, 2012) between 2007 and 2012. Information on the participants' disciplinary backgrounds, $\mathrm{PhD}$, and postdoctoral training institutions is available in Supplemental Material Tables S1-S3.

Although noncitizen postdocs are the majority of all postdocs in the United States, analysis of career development and interest was restricted to citizens and permanent residents because of issues (such as visa status) that uniquely shape their career decision making. The sampling strategy does not permit the calculation of a formal response rate; however, the sample represents $\sim 8.9 \%$ of eligible respondents (i.e., U.S. citizen and permanent resident postdocs in the life sciences, bioengineering, neuroscience, and psychology [henceforth, "biomedical sciences"] in 2012) and 18.8\% of eligible postdocs from URM backgrounds in this category (National Science Foundation, 2013).

Social Identity. Social identity was stratified based on the intersections of race/ethnicity and gender as previously described (Gibbs et al., 2014). Males from well-represented racial/ethnic backgrounds (i.e., white, Asian/Asian American, or both white and Asian/Asian American) are referred to as WRM (25.6\% of sample; $n=257)$; males from URM racial/ethnic (American Indian/Alaska Native, black/ African-American, Hispanic/Latino, or Native Hawaiian/ Pacific Islander) backgrounds are referred to as URMM (5.4\% of sample; $n=54)$; females from well-represented backgrounds are referred to as WRF (54.6\% of sample; $n=547)$; and females from URM backgrounds are referred to as URMF (12.2\% of sample; $n=122)$.

Career Interest Measures. Respondents reported their interest in four career pathways at three time points: 1) the beginning of their PhD training, 2) the completion of their PhD training, and 3) currently. These pathways were:

- Faculty at a research-intensive university

- Faculty at a teaching-intensive university

- Research career, nonacademic (e.g., industry, pharmaceutical, biotech, government, start-up)

- Nonresearch career (e.g., consulting, policy, science writing, patent law, business)

Interest was measured on a six-point scale, on which 0 represented not knowledgeable; 1 , no interest; 3 , moderate interest; and 5, strong interest. For this analysis, respondents answering not knowledgeable were recoded as having no interest. Sensitivity analysis revealed the inferences about career development did not change based on this reclassification. Those who answered 4 or 5 were considered "high interest" (see Figure 2 and Tables 1 and 2 later in this article).

Career Development, Training Experience, and Research SelfEfficacy Measures. Respondents rated their level of agreement with statements about their career goal clarity and knowledge of career options available to PhDs in their disciplines at three time points: 1) the beginning of their $\mathrm{PhD}$ training, 2) the completion of their PhD training, and 3) currently.
Respondents also rated their level of agreement with statements regarding their graduate and postdoctoral training experiences. Measures focused on self-reported:

- Sense of belonging, both intellectually and socially: This was assessed in respondents' 1) graduate research groups, 2) graduate departments, and 3) postdoctoral research groups.

- Advisor interactions: The extent to which respondents felt their graduate and postdoctoral advisors were 1) "invested" in their career advancement and 2) "equally supportive of [trainees] pursuing academic and non-academic career paths."

- Career development: The extent to which respondents 1) were "offered structured opportunities to explore a variety of career pathways (academic and non-academic)" by their graduate departments and postdoctoral institutions and 2) felt their graduate departments were "equally supportive of [trainees] pursuing academic and non-academic career paths."

- Research self-efficacy: This was assessed via the respondent's agreement with the statement "I am confident in my abilities as an independent researcher."

Agreement was measured on a five-point scale, on which 1 represented strongly disagree; 2 , disagree; 3 , neither agree nor disagree; 4, agree; and 5, strongly agree. For analytical purposes, those who answered 1 or 2 were considered "disagree," those who answered 3 were considered "neutral," and those who answered 4 or 5 were considered "agree" (see Figures 1 and 3 later in this article).

Statistical Analysis. Paired $t$ tests and repeated measures analysis of variance (ANOVA) were used to assess changes in levels of agreement across time points in the overall sample (Figure 1, A and B) and levels of interest within each social identity group (Figure 2) (Fagerland, 2012). The inferences provided by each method of analysis were identical. For Figure 1, A and B, level of agreement at PhD completion or currently (postdoc) was compared with the level of interest at $\mathrm{PhD}$ entry (pre-post tests). In Figure 2, within each social identity group, three comparisons were made: 1) PhD entry versus $\mathrm{PhD}$ completion (to examine changes during the course of graduate training), 2) $\mathrm{PhD}$ completion versus currently (to examine changes during the course of postdoctoral training), and 3) PhD entry versus currently (to examine changes from the beginning of graduate training to postdoctoral training). A Bonferroni-corrected ANOVA was used to compare differences in levels of agreement or career pathway interest between social identity groups at any time point.

Multiple logistic regression analysis was used to determine how career pathway interest was influenced by measures of the career development, training experiences, and research self-efficacy measures (for full details, see Gibbs et al., 2014). Additionally, objective measures (first-author publication rate [i.e., first-authored publications/total years in graduate and postdoctoral training] and total years in postdoctoral training) were also included in the models. Career interest measures at all time points (PhD entry, PhD completion, and currently) were dichotomized into high interest (i.e., 4-5), and low interest (1-3). SEs 


\section{(A) I had/have a clear career goal}

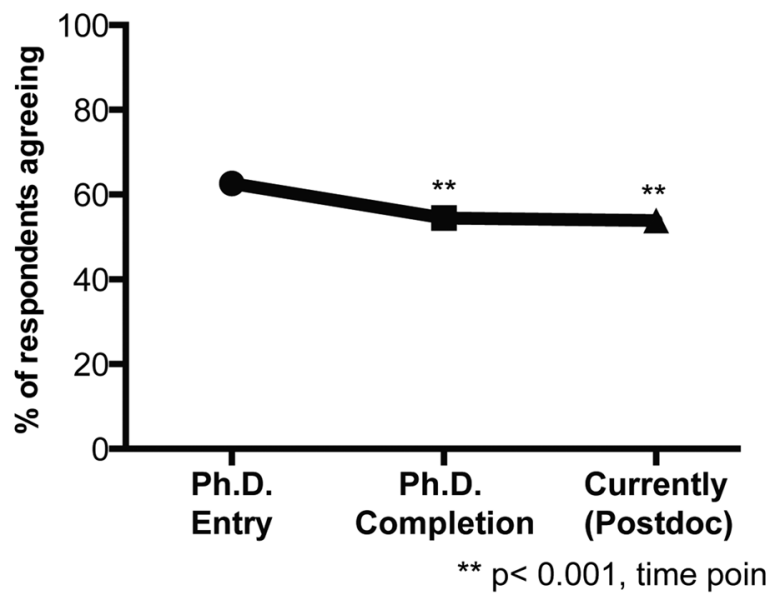

(B) I was/am knowledgable about the various career options available to a person with a Ph.D. in my discipline
(C) Offered structured opportunities to explore a variety of career pathways (academic \& non-academic)

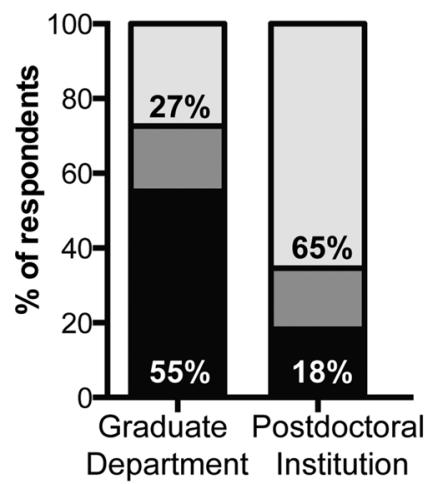

\section{(D) Equal support for pursuit of} academic \& non-academic careers

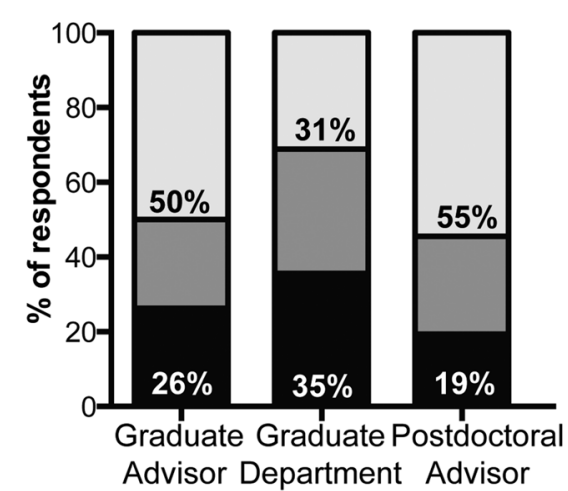

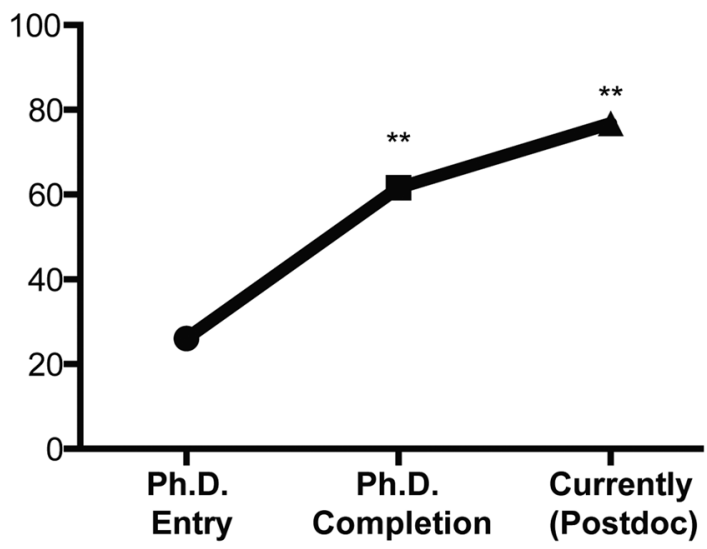

\section{Agree $\square$ Neutral $\square$ Disagree}

Figure 1. Career goal clarity, knowledge, and career development among postdocs. (A and B) Postdocs were asked to rate their agreement with statements regarding their (A) clarity about their career goals and (B) knowledge about their potential career options at $\mathrm{PhD}$ entry, $\mathrm{PhD}$ completion, and currently. Responses were rated on a five-point scale (1, strongly disagree; 3, neither agree nor disagree; and 5, strongly agree). Line charts show the percentage of respondents answering 4 or 5 (i.e., agree or strongly agree). Paired $t$ tests and repeated measures ANOVA were used to compare changes in the level of agreement during graduate training (PhD entry to PhD completion), and over the course of training (PhD entry to currently). Significant differences are shown. See Supplemental Material Tables S4-S6 for full data and statistical analysis underlying A and B. (C-E) Postdocs were asked to rate their level of agreement with statements regarding (C) the extent to which they received structured career development in their graduate department or postdoctoral institution; (D) the extent to which they found equal support for pursuit of academic and nonacademic careers from their graduate advisors, graduate department, or postdoctoral advisor; and (E) the extent to which their graduate and postdoctoral advisors were invested in their career. Responses were rated on a five-point scale (1, strongly disagree; 3, neither agree nor disagree; and 5, strongly agree). Bar charts show the percentage of respondents disagreeing with (black; 1 or 2), neutral about (3; gray), or agreeing with (white; 4 or 5) the statements. See Supplemental Material Table S7 for full data and statistical analysis and underlying C-E.

were adjusted to account for the potential clustering of responses by postdoctoral training institution. Social identity was coded using three indicator variables (URMM, WRF, and URMF), with WRM as the reference group. All statistical analysis was conducted using Stata, version 13.0, and figures were created using GraphPad Prism and Adobe Illustrator.
Limitations. There are a number of limitations to this work. First, the sample is nonrandom, thus the generalizability of the findings may be limited. While the sample of postdocs from URM backgrounds is large, the sample of URMM is sometimes underpowered and not able to adequately capture potential differences between their responses and those of postdocs from other groups. The survey did not ask 
(A) Faculty, Research-intensive
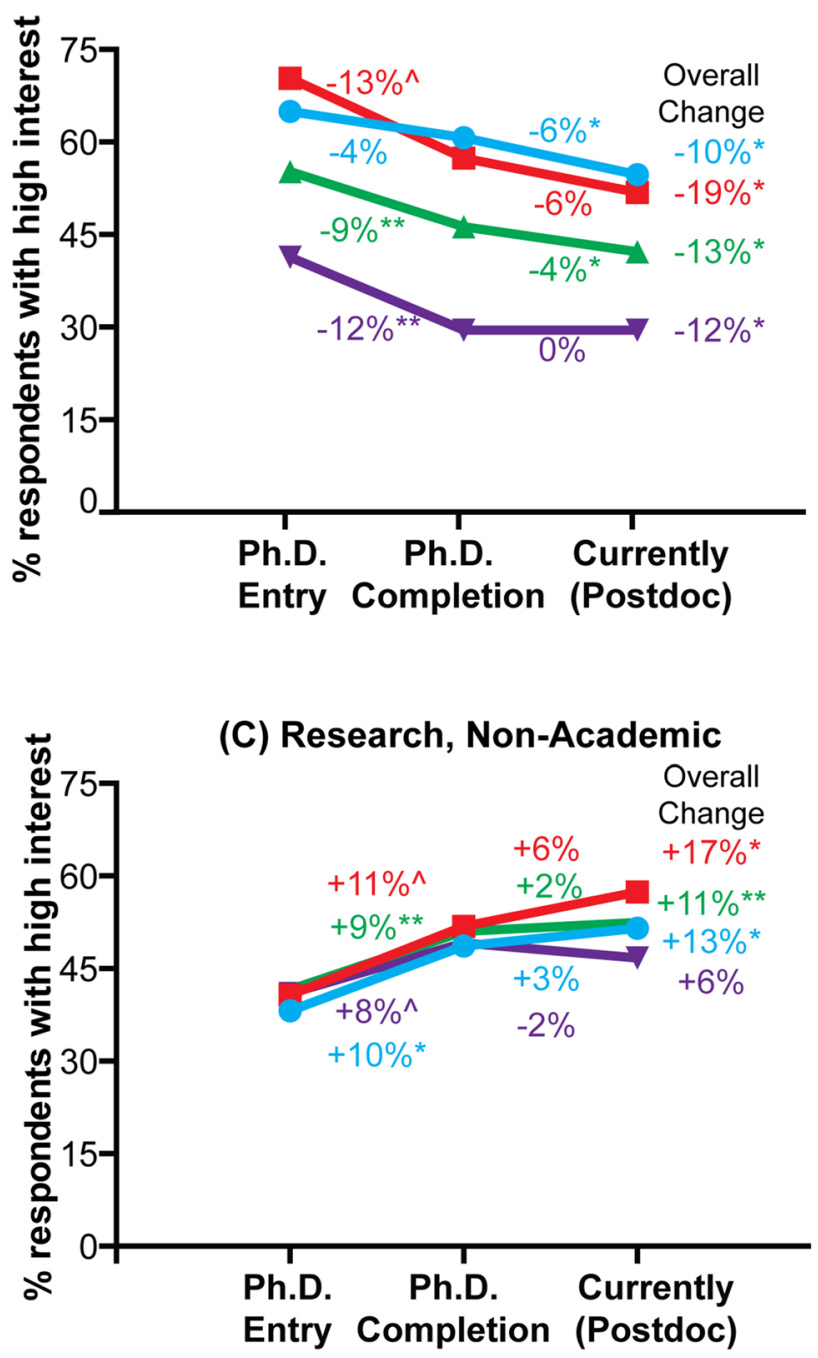

Well-represented, Male (WRM; $n=257$ )

Well-represented, Female (WRF; $n=547$ )
(B) Faculty, Teaching-intensive
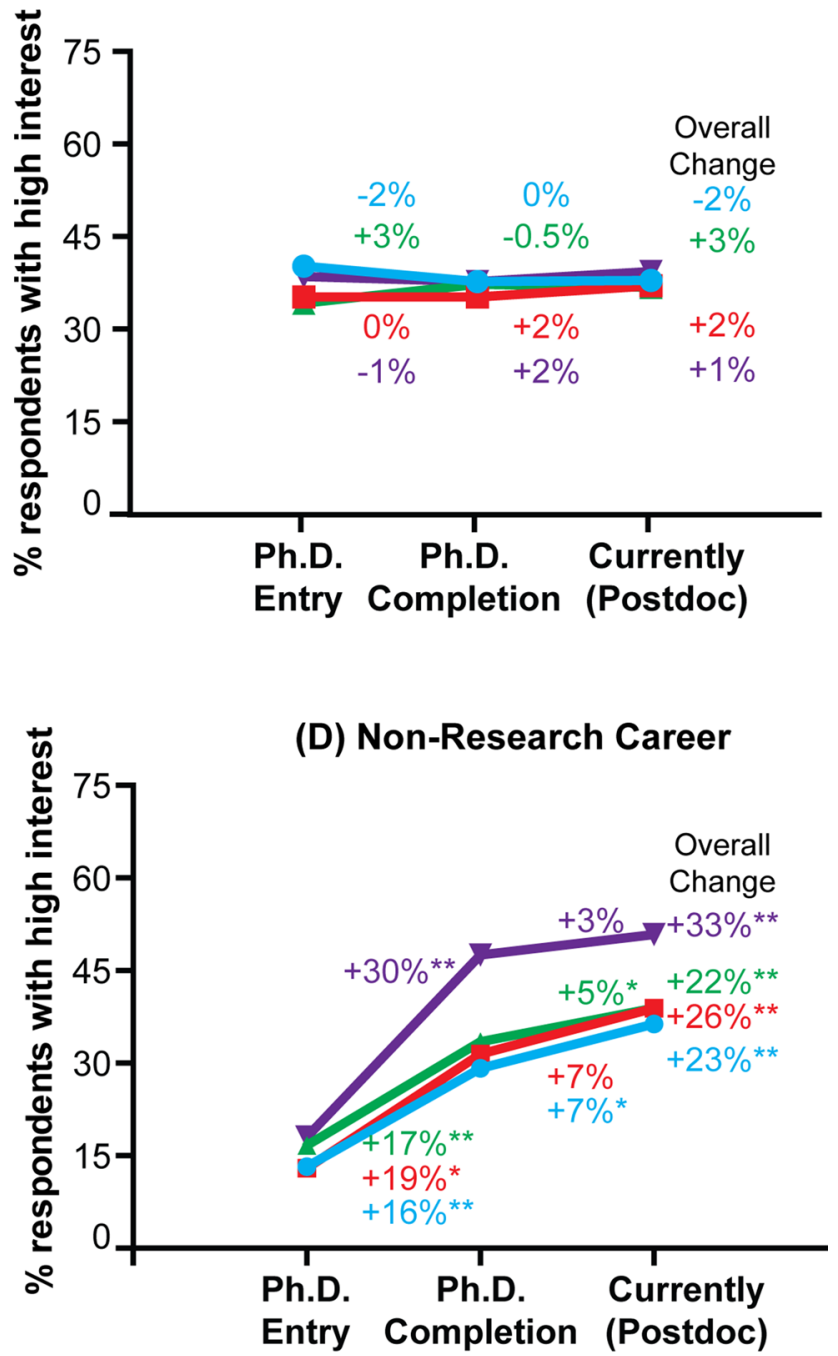

Underrepresented Minority, Male (URMM; $n=54)$

Underrepresented Minority, Female (URMF; $n=122)$

Level of significance (within group change over time period): ${ }^{* *} p<0.001{ }^{*} p<0.05{ }^{\wedge} p<0.10$

Figure 2. Changes in career interest patterns across the course of training, by social identity. Postdocs were asked to rate their of level interest on a five-point scale (1, no interest; 5 , strong interest) in (A) a faculty position at a research-intensive university, (B) a faculty position at a teaching intensive university, (C) a research career outside academia (e.g., industry, pharmaceutical, biotech, government, start-up), and (D) a nonresearch career (consulting, policy, science writing, patent law, business, etc.) at PhD entry, PhD completion, and currently. Line graphs show the percentage of respondents from each social group reporting high levels of interest (i.e., 4 or 5). The percentage change in each training segment (i.e., from PhD entry to PhD completion; from PhD completion to postdoc) and the overall change (i.e., from PhD entry to currently) are shown. Statistical significance for changes in interest for each group and during each training segment were determined using paired $t$ tests and repeated measures ANOVA. Full statistical analysis is shown in Supplemental Material Table S8.

about family status (i.e., marriage/partnership, children, and plans for children), which has previously been linked to career attainment in science trainees (Goulden et al., 2009). Additionally, this work relies on self-reported measures of career interest and training experiences, and respondents may have attempted to provide answers that are socially acceptable. We addressed this as previously described (Gibbs et al., 2014). Finally, respondents were asked, in some cases, to retrospectively assess their career interests and training experiences, introducing the potential for incomplete/inaccurate recollections or recall bias. However, understanding respondents' perceptions of their experiences is important as these are linked to measurable educational and vocational outcomes important for workforce policy such as persistence, goal setting, academic achievement, and satisfaction (Hurtado et al., 1999; Lizzio et al., 2002; Eva et al., 2010). 


\section{RESULTS}

\section{Postdocs Reported Lower Career Goal Clarity and Enhanced Knowledge of Career Options Relative to PhD Entry}

Our previous work indicated that $\mathrm{PhD}$ scientists often pursued graduate and postdoctoral training without clear career goals and without full knowledge about their potential career options (Gibbs and Griffin, 2013). For this study, respondents were asked to rate their level of agreement at $\mathrm{PhD}$ entry, $\mathrm{PhD}$ completion, and currently (i.e., during their postdoc) with the following statements: "I had/have a clear career goal," and "I was/am knowledgeable about the career options available to a person with a PhD in my discipline." The percentages of postdocs indicating agreement (i.e., a 4 or 5) are shown in Figure 1, A and B.

Overall, at PhD entry, $63 \%$ of respondents indicated they had a clear career goal; however, only $26 \%$ of postdocs reported having knowledge about the career options available to a person with a $\mathrm{PhD}$ in their discipline when they began their PhD training (Figure 1, A and B). A cross-tabulation of these two questions (Supplemental Material Table S4) shows that the majority of those who indicated having a clear career goal at PhD entry $(n=321 / 627$ or $51 \%)$ also reported poor knowledge of career options, and only $19 \%$ of respondents felt they entered their $\mathrm{PhD}$ programs with both a clear career goal and knowledge of career options. As training progressed, greater percentages of postdocs reported knowledge about potential career options $(62 \%$ at $\mathrm{PhD}$ completion and $77 \%$ currently; $p<0.001$ when comparing knowledge at PhD completion and currently to PhD entry; Figure 1B), yet fewer postdocs reported having clarity about their career goals $(54 \%$ agreed that they had a clear career goal both at PhD completion and currently; $p<0.001$ when comparing clarity at $\mathrm{PhD}$ completion and currently with $\mathrm{PhD}$ entry). Of note, even though overall career goal clarity decreased, the percentage of those reporting both career goal clarity and knowledge about career options increased to $47 \%$ (Supplemental Material Table S5). Collectively, these results suggest early perceptions of career goal clarity occur alongside little knowledge about potential career options available to biomedical PhDs. Further, despite having on average $8 \mathrm{yr}$ of postbaccalaureate training ( $6 \mathrm{yr} \mathrm{PhD}, 2 \mathrm{yr}$ postdoctoral training) and enhanced knowledge about available careers, fewer postdocs reported having high levels of career goal clarity than when they started their PhDs. Full data and statistical analysis underlying Figure 1, A and B, are available in Supplemental Material Table S6.

To understand the broader environment in which their career development occurred, postdocs were asked about 1) opportunities for structured career exploration during their graduate and postdoctoral training, 2) the departmental and institutional support offered for pursuit of the full range of career options available to biomedical $\mathrm{PhDs}$, and 3) advisor investment in their career advancement (Figure 1, C-E). Fewer than one-third of respondents (27\%) reported that they were offered "structured opportunities to explore a variety of career pathways (academic and non-academic)" by their graduate departments, while nearly two-thirds $(65 \%)$ reported being offered these structured opportunities for career exploration by their postdoctoral institutions (Figure 1C). Thus, while postdocs reported significant gains in knowledge about career options during graduate school (Figure 1B), these responses suggest that their learning occurred largely outside graduate departments and programs.

Respondents were also asked whether graduate advisors, graduate departments, or postdoctoral advisors were "equally supportive" of students or postdocs "pursuing academic and non-academic career paths" (Figure 1D). Half of the respondents reported their graduate advisors supported all career paths $(50 \%)$, while fewer than one-third $(31 \%)$ agreed that their graduate departments were equally supportive of students pursuing all career paths, and slightly more than half $(55 \%)$ reported their postdoctoral advisors supported postdocs pursuing all career paths. In contrast, three-quarters $(75 \%)$ of respondents reported that their graduate and postdoctoral advisors were "invested in [their] career advancement" (Figure 1E). Collectively, these results indicate that biomedical $\mathrm{PhDs}$ perceive their advisors as supportive of their career development generally but that there is less support for the pursuit of a broad range of career pathways from advisors and departments. Of note, the levels of career goal clarity, knowledge, advisor investment, support for pursuit of all career pathways, and structured career development were largely consistent across social identity (i.e., race/ ethnicity and gender; see Supplemental Material Table S7), suggesting that these factors are largely shared for graduate students and postdocs from all backgrounds.

\section{Overall Changes in Career Pathway Interests across Social Identity}

Postdocs described their level of interest in four career pathways across the course of their training: 1) faculty at a research-intensive university, 2) faculty at a teaching-intensive university, 3) a research career outside academia, (e.g., industry, pharmaceutical, biotech, government, or a start-up), or 4) a nonresearch career, (e.g., consulting, policy, science writing, patent law, or business). The percentage of postdocs who reported high interest (i.e., a 4 or 5) at PhD entry, PhD completion, and currently is shown in Figure 2 (full data and statistical analysis underlying this figure are available in Supplemental Material Table S8).

Trends in career interests were largely shared across lines of social identity. For all groups, the percentage of postdocs reporting high interest in faculty careers at research universities declined significantly over the course of their training $(-10-19 \%$ from PhD entry to postdoc, $p<0.02$ when comparing levels of interest across time within each social group; Figure 2A); the percentage reporting high interest in faculty careers at teaching universities was unchanged (Figure 2B); the percentage reporting high interest in research careers outside academia increased significantly for WRM, WRW, and URMM $(+11-17 \%, p<0.02$ for within-group changes across time; Figure $2 \mathrm{C}$ ); and the percentage reporting high interest in careers outside research increased significantly $(+22-33 \% ; p<0.0002$ for within-group changes; Figure 2D).

There were some notable differences across social identity with respect to both the magnitude and period of training in which changes in interest occurred. During graduate training, there were significant declines in the percentage of women and URM men who expressed high levels of interest in faculty careers at research universities (URMM: $-13 \%$, 
$p=0.051$; WRF: $-9 \%, p<0.0001$; URMF: $-12 \%, p<0.02)$; however, there were not significant changes for WRM $(-4 \%$; $p=0.20$ ). During postdoctoral training, there were significant declines in the percentage of scientists from well-represented backgrounds reporting high interest in research faculty careers (WRM: $-6 \%, p=0.01$; WRF: $-4 \% ; p=0.008$ ) but not for postdocs from URM backgrounds (URMM: $-6 \%$, $p=0.3$; URMF: $0 \%, p=1.0$; Figure 2A). Thus, with respect to interest in faculty careers at research-intensive universities, graduate training appears to be a particularly important time for the development of career interests for women and URM men, while well-represented men may, on average, be engaging in more career decision making during their postdoctoral training. Similar patterns are observed for interest in careers outside research. The increase in the percentage of URMF reporting high interest between PhD entry and completion was greater than that for other groups $(+30 \%$ for URMF vs. $+16-19 \%$ for other groups, $p<0.004$ when comparing the pre-post change of URMF with all other groups; Figure 2D).

\section{Different Senses of Social "Belonging" and Research Self-Efficacy across Social Identity}

Participants' graduate and postdoc training experiences were also assessed to understand potential factors influencing differences in career interest patterns. We focused on questions related to sense of belonging and research self-efficacy. Postdocs were asked the extent to which they felt they belonged intellectually and socially to their 1) graduate school research group, 2) graduate school department, and 3) postdoctoral research group (Figure 3, A and B). There were no statistically significant differences across groups in the percentage of postdocs who reported belonging intellectually to their graduate research group (average $87 \%$ agreement; Figure $3 \mathrm{~A}, \mathrm{i})$, belonging intellectually to their postdoctoral research group (average $84 \%$ agreement; Figure $3 \mathrm{~A}$, iii), or belonging socially to their postdoctoral research group (average $63 \%$ agreement; Figure 3B, iii). There were, however, statistically significant differences across social groups in the levels of reported intellectual belonging in their graduate department (Figure 3A, ii; $p<0.03$ ), social belonging in their graduate research group (Figure $3 \mathrm{~B}, \mathrm{i} ; p<0.001$ ), and social belonging in their graduate departments (Figure 3B, ii; $p=0.02$ ). In each case, women from URM backgrounds reported the lowest levels of belonging. With respect to social belonging in graduate school, the percentage of URMF who reported belonging was $13-21 \%$ lower than their peers (Figure 3B, i and ii), and fewer than half of URMF postdocs (48\%) reported feeling that they belonged socially in their graduate departments.

Postdocs were also asked their research self-efficacy, that is, the extent to which they agreed with the statement "I am confident in my abilities as an independent researcher" (Figure 2C). While more than $60 \%$ of postdocs from all social groups reported having confidence in their research abilities, there were again differences by social identity. Men reported higher levels of research self-efficacy than women (WRM: 83\%; URMM: 87\%), and URMF reported the lowest levels of research self-efficacy (URMF: 63\%; WRF: 72\%). These group differences in levels of research self-efficacy remained even when accounting for research productivity (i.e., number of first-authored, peer-reviewed publications normalized for amount of time in training; unpublished data).

\section{Different Patterns of Career Interest Development among Male and Female Postdocs Occur in Graduate School}

Statistical modeling was used to describe the relationships between these factors and career interests, and to determine whether any of these factors might explain differences in career interest patterns by social identity. Specifically, we used logistic regression analysis, in which the likelihood that a postdoc would express high interest in each career pathway (i.e., answer 4 or 5 on the interest scale) was the outcome/dependent variable. Four models were tested. Each model incorporated social identity, with the career interests of WRM serving as the reference group. Subsequent models incorporated factors such as research productivity and research self-efficacy (model 2), a postdoc's career interest at PhD completion (model 3), and training experiences (model 4). Results of the models for faculty careers at research universities and nonresearch careers are shown in Tables 1 and 2, respectively (results for faculty at a teaching-intensive university and a research career outside academia are shown in Supplemental Material Tables S9 and S10).

With respect to faculty careers in research-intensive universities, career interests at $\mathrm{PhD}$ completion were able to account for postdoc males' higher levels of interest when compared with females. Among the postdocs in the study, URMM postdocs were as likely as WRM to report high interest (odds ratio [OR]: $0.89 ; 95 \%$ confidence interval [CI]: 0.53-1.49; $p=0.66)$; however, on average, WRF were $39 \%$ less likely (OR: $0.61 ; 95 \%$ CI: $0.48-0.76 ; p<0.001$ ) and URMF were $65 \%$ less likely (OR: 0.35 ; 95\% CI: $0.23-0.53$; $p<0.0001$ ) to report high interest (Table 1, model 1). Both research self-efficacy (OR: 2.94; 95\% CI: 2.31-3.72; $p<0.001$ ) and research productivity (OR: 3.70 ; 95\% CI: 2.23-6.13; $p<0.001)$ were positively associated with interest in faculty careers in research-intensive universities (Table 1, model 2). However, after controlling for these factors, WRF remained $30 \%$ less likely (OR: $0.70 ; 95 \%$ CI: $0.54-0.89 ; p<0.004$ ) and URMF were $54 \%$ less likely (OR: 0.46 ; 95\% CI: $0.30-0.70$; $p<0.001$ ) than WRM to express high interest in faculty positions at research-intensive universities (Table 1, model 2). In other words, postdoc women with productivity and research self-efficacy similar to their male counterparts were less likely to express interest in a faculty career at a research-intensive institution. When taking into account whether or not a postdoc had high interest in this career path at PhD completion (OR: 41.72; 95\% CI: 28.14-61.84; $p<0.001$ ), there were no longer differences in interest by social identity (Table 1, model 3 ). Thus, our analysis suggests the observed differences in interest by social identity group are explained by women's lower levels of interest in faculty careers at the end of graduate school. Model 4 showed that interest at PhD completion remained the strongest predictor of high interest in a faculty career currently (OR: 38.43; 95\% CI: 23.25-63.49; $p<0.001$ ), even when accounting for other variables such as postdoctoral advisor investment (OR: $1.61 ; p<0.05)$, research self-efficacy (OR: 2.50; $p<0.001$ ), and research productivity (OR: $2.52 ; p<0.05$ ). 
(i) Graduate School Research Group

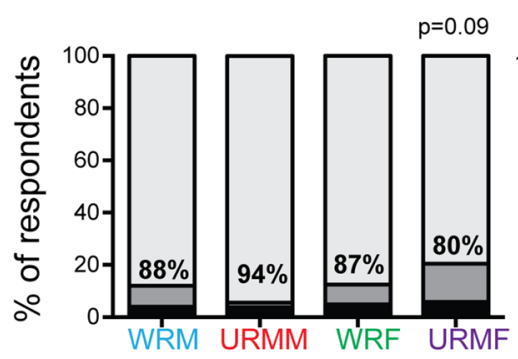

(B) (ii) Graduate School Department

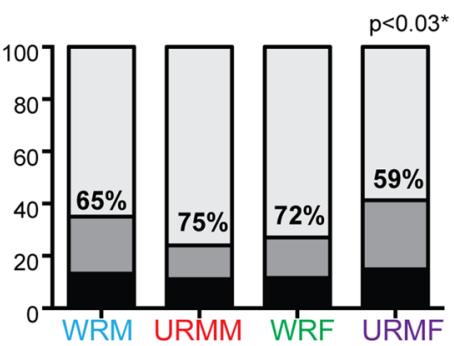

(iii) Postdoctoral Research Group

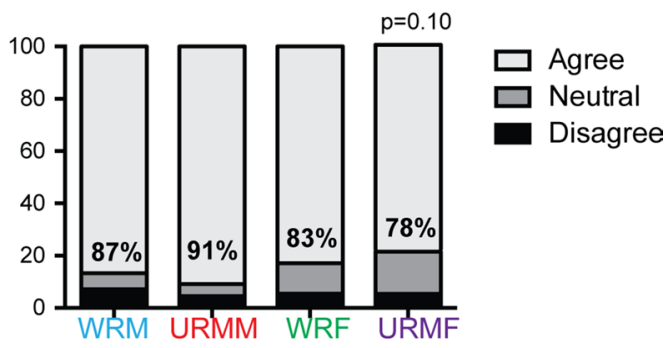

\section{I belonged to the social community of...}

(i) Graduate School Research Group

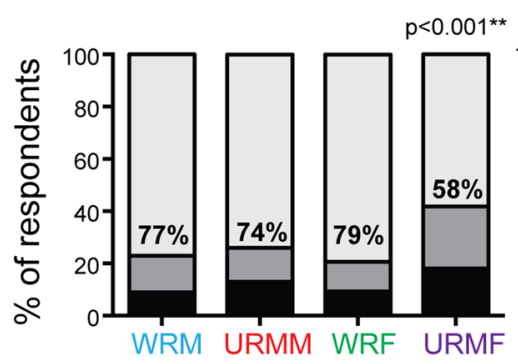

(ii) Graduate School Department

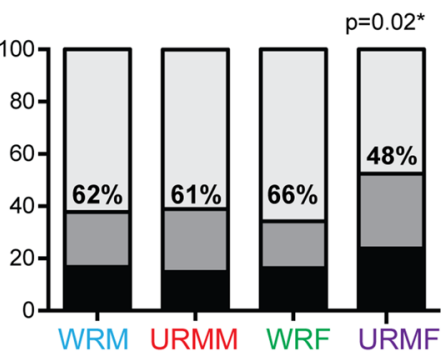

(iii) Postdoctoral Research Group

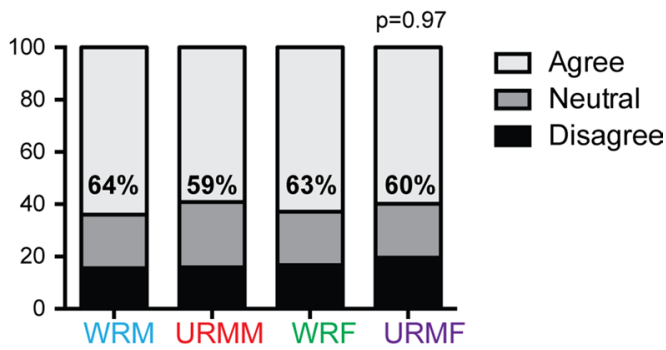

(C)

\section{I am confident in my abilities as an independent researcher}

(i.e. research self-efficacy)

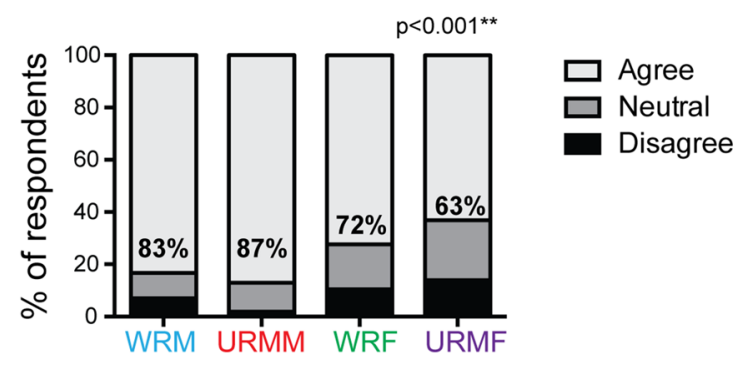

Well-represented, Male (WRM; $\mathrm{n}=257$ )

Well-represented, Female (WRF; n=547)
Underrepresented Minority, Male (URMM; $n=54)$

Underrepresented Minority, Female (URMF; $n=122$ )

Figure 3. Different senses of social belonging and research self-efficacy reported across social identity. Postdocs were asked to rate their level of agreement with statements regarding their sense of (A) intellectual and (B) social belonging in their (i) graduate school research group, (ii) graduate school department, and (iii) postdoctoral research group. (C) Postdocs were also asked the extent to which they had confidence in their ability as independent researchers (i.e., research self-efficacy). Responses were rated on a five-point scale (1, strongly disagree; 3 , neither agree nor disagree; and 5, strongly agree). Bar charts show the percentage of respondents from each social identity groups disagreeing (black; 1 or 2), neutral (3; gray), or agreeing (white; 4 or 5 ) with the statements. For each question, the responses between social groups were compared using the chi-square test, and the level of significance is shown.

Thus, in this sample of postdocs, women's lower levels of interest in faculty careers at research universities at PhD completion explains much of their lower levels of interest as postdocs.

Similarly, the higher interest of URMF in careers outside research relative to other groups (Table 2, model 1) appears to be explained by differences that occur during graduate training. In the regression analyses assessing factors influencing interest in careers outside research, models 3 and 4 show that high interest at PhD completion strongly predicts high interest currently, and, when this is accounted for, there are no longer significant differences among postdocs of different backgrounds. Thus, the higher level of interest of URMF currently is largely explained by their high level of 
Table 1. Logistic regression analysis of factors associated with postdocs expressing high interest in faculty careers at research-intensive universities $^{\mathrm{a}}$

\begin{tabular}{|c|c|c|c|c|c|}
\hline \multirow[b]{2}{*}{ Covariate class } & \multirow[b]{2}{*}{ Covariate } & \multicolumn{4}{|c|}{ Career pathway: faculty, research-intensive university } \\
\hline & & Model 1 & Model 2 & Model 3 & Model 4 \\
\hline \multirow[t]{4}{*}{ Social identity } & WRM & Reference & Reference & Reference & Reference \\
\hline & URMM & $0.89(0.53-1.49)$ & $0.89(0.50-1.59)$ & $0.97(0.44-2.18)$ & $1.38(0.59-3.22)$ \\
\hline & WRF & $0.61(0.48-0.76)^{* *}$ & $0.70(0.54-0.89)^{*}$ & $0.86(0.55-1.31)$ & $0.93(0.58-1.49)$ \\
\hline & URMF & $0.35(0.23-0.53)^{* *}$ & $0.46(0.31-0.70)^{* *}$ & $0.80(0.42-1.52)$ & $1.25(0.62-2.51)$ \\
\hline \multirow[t]{2}{*}{ Personal disposition } & $\begin{array}{l}\text { High career pathway interest at } \\
\text { PhD completion }\end{array}$ & & & $41.72(28.14-61.84)^{* *}$ & $38.43(23.25-63.49)^{* *}$ \\
\hline & $\begin{array}{l}\text { Research self-efficacy (i.e., } \\
\text { confidence in ability as an } \\
\text { independent researcher) }\end{array}$ & & $2.94(2.31-3.72)^{* *}$ & & $2.50(1.69-3.69)^{* *}$ \\
\hline \multirow[t]{2}{*}{ Objective } & $\begin{array}{l}\text { First-author publication rate } \\
\text { (publications/years in } \\
\text { training) }\end{array}$ & & $3.70(2.23-6.13)^{* *}$ & & $2.52(1.42-4.49)^{*}$ \\
\hline & $\begin{array}{l}\text { Total time in postdoctoral } \\
\text { training (years) }\end{array}$ & & & & $0.90(0.77-1.05)$ \\
\hline \multirow{6}{*}{$\begin{array}{l}\text { Postdoctoral training } \\
\text { experiences (sense of } \\
\text { belonging, advisor } \\
\text { support, career } \\
\text { development) }\end{array}$} & $\begin{array}{l}\text { Intellectual belonging, research } \\
\text { group } \\
\text { Social belonging, research } \\
\text { group }\end{array}$ & & & & $1.11(0.77-1.59)$ \\
\hline & $\begin{array}{l}\text { Postdoctoral advisor invested } \\
\text { in career advancement }\end{array}$ & & & & $1.10(0.85-1.44)$ \\
\hline & Postdoctoral advisor equally & & & & $1.61(1.16-2.22)^{*}$ \\
\hline & $\begin{array}{l}\text { supportive of students } \\
\text { pursuing academic and } \\
\text { nonacademic career paths }\end{array}$ & & & & $1.20(0.88-1.62)$ \\
\hline & $\begin{array}{l}\text { Institution offered structured } \\
\text { opportunities to explore a } \\
\text { variety of career pathways }\end{array}$ & & & & $0.93(0.67-1.30)$ \\
\hline & $\begin{array}{l}\text { Institution offered structured } \\
\text { opportunities to develop } \\
\text { nonresearch skills }\end{array}$ & & & & $1.15(0.84-1.59)$ \\
\hline
\end{tabular}

\footnotetext{
aAdjusted odds ratios (and 95\% CI) shown. Likelihood of expressing high interest in career path across social identity, adjusted for: model 1: unadjusted; model 2: research self-efficacy and productivity; model 3: high interest in career pathway at PhD completion; and model 4: high interest in career pathway at $\mathrm{PhD}$ completion, research self-efficacy, objective measures, and postdoctoral training experiences.

${ }^{*} p<0.05 ;{ }^{* *} p<0.001$.
}

interest in nonresearch careers at the end of their graduate training. Beyond interest at PhD completion, high levels of interest in careers outside research were inversely associated with postdoctoral advisor career investment (OR: 0.58; 95\% CI: $0.43-0.77 ; p<0.001)$ and positively associated with longer length of time in postdoctoral training (OR: 1.20;95\% CI: $1.03-1.39 ; p<0.02)$. In other words, holding all other factors constant, a fifth-year postdoc was 2.5 times more likely than a first-year postdoc to express high interest in a career outside research. Collectively, these results show that the group differences in the career interests of postdocs can be explained by differences in career interests at PhD completion.

\section{DISCUSSION}

Postdoctoral scientists are critical to the research enterprise but remain understudied. This survey of American postdocs was done in an effort to illuminate their career development and to inform the ongoing efforts to enhance biomedical training and workforce diversity. The findings of this research have implications for our understanding of postdocs' knowledge about career options, their diverse patterns of career development, and the factors related to their career choices.

First, these results point to the need for enhanced career development over the full course of scientific training. Our findings suggest that trainees start graduate school with little knowledge about the various careers they could pursue with their degrees. While the increase in the number of participants who feel knowledgeable about their career options throughout their training is significant and notable, clarity about career goals declines during this time. Further, much of what trainees learn before their postdoctoral appointments appears to be outside formal programming in their respective departments. Given that increased access to information does not appear to translate to increased certainty about one's career path, it is important to consider whether traditional career development opportunities that 
Table 2. Logistic regression analysis of factors associated with postdocs expressing high interest in nonresearch careers ${ }^{\mathrm{a}}$

\begin{tabular}{|c|c|c|c|c|c|}
\hline \multirow[b]{2}{*}{ Covariate class } & \multirow[b]{2}{*}{ Covariate } & \multicolumn{4}{|c|}{ Career pathway: nonresearch career } \\
\hline & & Model 1 & Model 2 & Model 3 & Model 4 \\
\hline \multirow[t]{4}{*}{ Social identity } & WRM & Reference & Reference & Reference & Reference \\
\hline & URMM & $1.12(0.68-1.84)$ & $1.05(0.59-1.86)$ & $1.08(0.54-2.18)$ & $1.01(0.42-2.48)$ \\
\hline & WRF & $1.12(0.88-1.41)$ & $1.04(0.81-1.34)$ & $0.97(0.68-1.37)$ & $1.01(0.66-1.56)$ \\
\hline & URMF & $1.81(1.02-3.21)^{*}$ & $1.51(0.83-2.76)$ & $1.14(0.63-2.06)$ & $0.79(0.42-1.48)$ \\
\hline \multirow[t]{2}{*}{ Personal disposition } & $\begin{array}{l}\text { High career pathway interest at } \\
\text { PhD completion }\end{array}$ & & & $32.09(19.11-53.88)^{* *}$ & $31.62(19.10-52.36)^{* *}$ \\
\hline & $\begin{array}{l}\text { Research self-efficacy (i.e., } \\
\text { confidence in ability as an } \\
\text { independent researcher) }\end{array}$ & & $0.66(0.53-0.80)^{* *}$ & & $0.75(0.51-1.13)$ \\
\hline \multirow[t]{2}{*}{ Objective } & $\begin{array}{l}\text { First-author publication rate } \\
\quad \text { (publications/years in training) }\end{array}$ & & $0.51(0.33-0.78)^{*}$ & & $1.07(0.55-2.08)$ \\
\hline & $\begin{array}{l}\text { Total time in postdoctoral training } \\
\text { (years) }\end{array}$ & & & & $1.20(1.03-1.39)^{*}$ \\
\hline \multirow[t]{5}{*}{$\begin{array}{l}\text { Postdoctoral training } \\
\text { experiences (sense of } \\
\text { belonging, advisor } \\
\text { support, career } \\
\text { development) }\end{array}$} & $\begin{array}{l}\text { Intellectual belonging, research } \\
\text { group } \\
\text { Social belonging, research group } \\
\text { Postdoctoral advisor invested in } \\
\text { career advancement }\end{array}$ & & & & $0.79(0.54-1.14)$ \\
\hline & Postdoctoral advisor equally & & & & $1.10(0.85-1.45)$ \\
\hline & $\begin{array}{l}\text { supportive of students pursuing } \\
\text { academic and nonacademic } \\
\text { career paths }\end{array}$ & & & & $\begin{array}{c}0.58(0.43-0.77)^{* *} \\
1.03(0.76-1.39)\end{array}$ \\
\hline & $\begin{array}{l}\text { Institution offered structured } \\
\text { opportunities to explore a } \\
\text { variety of career pathways }\end{array}$ & & & & $1.12(0.81-1.54)$ \\
\hline & $\begin{array}{l}\text { Institution offered structured } \\
\text { opportunities to develop } \\
\text { nonresearch skills }\end{array}$ & & & & $0.91(0.65-1.26)$ \\
\hline
\end{tabular}

aAdjusted odds ratios (and 95\% CI) shown. Likelihood of expressing high interest in career path across social identity, adjusted for: model 1: unadjusted; model 2: research self-efficacy and productivity; model 3: high interest in career pathway at PhD completion; and model 4: high interest in career pathway at $\mathrm{PhD}$ completion, research self-efficacy, objective measures, and postdoctoral training experiences.

${ }^{*} p<0.05 ;{ }^{* *} p<0.001$.

provide access to information about options (e.g., seminars and panels) are meeting trainees' needs. In addition to information, these findings suggest the need for departments and universities to implement more structured opportunities for trainees to reflect critically on what career paths best meet their needs, values, and interests, and to offer more opportunities to begin to explore those career paths (e.g., experiential learning). A number of institutions have begun to do this through mechanisms such as the NIH BEST awards $(\mathrm{NIH}$, $2014 \mathrm{~b}$ ), and these results suggest a need for efforts like this to be expanded.

The findings also suggest a misalignment between when career decisions are made and structured career development is offered. While postdocs' career interests were largely formed during graduate training, they did not report having been offered structured career development during this time. Instead, their postdoctoral institutions offered structured career development. While career development of postdoctoral scientists will continue to be important, these results reinforce the recommendation of the National Academies postdoc report that "beginning in the first year of graduate school, [host institutions and mentors should] make graduate students aware of the wide variety of career paths available for PhD recipients" (NAS, 2014, p. 4). Moreover, the poor knowledge of career options reported at PhD entry suggests that enhanced career development at the undergraduate level may also be beneficial.

Earlier opportunities to reflect critically on career options and interests may be particularly important for trainees from groups underrepresented in the research workforce (women and URM). Recent efforts at broadening participation have focused primarily on enhancing the number of scientists from URM backgrounds who complete PhDs and mentoring to support students from these populations (NIH, 2014a). While the postdocs in this study did not report significant differences in advisor relationships across social groups, there were clearly gendered differences in the career interests. Women were less likely-and URMF particularly less likely - than men to show interest in faculty careers at research universities, and these differences remained when accounting for any differences in research self-efficacy or productivity. Interestingly, among postdoc men, the career interests of the URM largely mirrored those well-represented men-a notable difference from the wider pool of PhD graduates (Gibbs et al., 2014). Racial and gender differences in this career path were no longer significant once level of interest in pursuing a faculty career at a research university at the end of graduate school was controlled. These findings, coupled with the descriptive analyses of participants' career paths, suggest that 
much of the career decision making for URMF and WRF scientists takes place during graduate school. We have completed in-depth interviews with nearly 70 survey respondents representing a diversity of social backgrounds (WR and URM men and women) and career pathways (academic and nonacademic). Subsequent analyses will focus on the factors (personal, institutional, and structural) that may be causing these unique patterns of career development such that institutions and federal agencies to can craft policies to make research careers attractive to trainees from all backgrounds.

Enhanced career development earlier in training could help alleviate the so-called glut of postdocs (Davis, 2005; Kaplan, 2012), better equipping trainees to start their careers with greater clarity after $\mathrm{PhD}$ completion. The NAS (2014) recommended that postdoctoral positions be "only for those seeking advanced research training" (p. 4) and that they "should not be viewed ... as the default step after the completion of doctoral training" (p. 5). However, a large percentage of the postdocs in this sample pursued postdoctoral positions, despite having interests in careers outside research. Thus, these data suggest there are many trainees in the current postdoctoral pool who are not preparing exclusively for faculty careers (or even careers in research). These results reinforce the need for biomedical graduate and postdoctoral training to adapt so that trainees can learn about and develop the skills necessary for the full range of careers available, considering both their interests and the realities of the academic job market.

\section{ACKNOWLEDGMENTS}

We thank Keith Micoli, Chris Pickett, and Sibby Anderson-Thompkins for their thoughtful feedback before submission. This work was supported, in part, by a generous grant from the Burroughs Wellcome Fund (Grant Number 1011798). The funders had no role in study design, data collection and analysis, decision to publish, or preparation of the manuscript. K.D.G. is a member of the board of directors for the National Postdoctoral Association. Findings and views expressed in this work are those of the authors alone and do not necessarily reflect the views of any organization with which they are affiliated.

\section{REFERENCES}

Alberts B, Kirschner MW, Tilghman S, Varmus H (2014). Rescuing US biomedical research from its systemic flaws. Proc Natl Acad Sci USA $111,5773-5777$.

Chemers MM, Zurbriggen EL, Syed M, Goza BK, Bearman S (2011). The role of efficacy and identity in science career commitment among underrepresented minority students. J Soc Issues 67, 469-491.

Daniels RJ (2015). A generation at risk: young investigators and the future of the biomedical workforce. Proc Natl Acad Sci USA 112, 313-318.

Davis G (2005). Doctors without orders. American Scientist 93(3), Supplement.

Eva KW, Munoz J, Hanson MD, Walsh A, Wakefield J (2010). Which factors, personal or external, most influence students' generation of learning goals? Acad Med 85 (Suppl 10), S102-S105.

Fagerland MW (2012). t-Tests, non-parametric tests, and large studiesa paradox of statistical practice? BMC Med Res Methodol 12, 78.

Ferrini-Mundy J (2013). Science education. Driven by diversity. Science 340, 278.
Fuhrmann CN, Halme DG, O'Sullivan PS, Lindstaedt B (2011). Improving graduate education to support a branching career pipeline: recommendations based on a survey of doctoral students in the basic biomedical sciences. CBE Life Sci Educ 10, 239-249.

Gibbs KD Jr., Griffin KA (2013). What do I want to be with my PhD? The roles of personal values and structural dynamics in shaping the career interests of recent biomedical science $\mathrm{PhD}$ graduates. $\mathrm{CBE}$ Life Sci Educ 12, 711-723.

Gibbs KD Jr., McGready J, Bennett JC, Griffin K (2014). Biomedical science $\mathrm{PhD}$ career interest patterns by race/ethnicity and gender. PLoS One 9, e114736.

Goulden M, Frasch K, Mason MA (2009). Staying Competitive: Patching America's Leaky Pipeline in the Sciences, Washington, DC: Center for American Progress.

Handelsman J, Cantor N, Carnes M, Denton D, Fine E, Grosz B, Hinshaw V, Marrett C, Rosser S, Shalala D, Sheridan J (2005). Careers in science. More women in science. Science 309, 1190-1191.

Harris R (2014). Too few university jobs for America's young scientists. National Public Radio. www.npr.org/blogs/health/2014/ 09/16/343539024/too-few-university-jobs-for-americas-youngscientists (accessed 15 January 2015).

Hausmann LRM, Schoenfield JW, Woods RL (2007). Sense of belonging as a predictors of intentions to persist among African American and white first-year college students. Res High Educ 48, 803-839.

Hurtado S, Carter DF (1997). Effects of college transition and perceptions of the campus racial climate on Latino college students' sense of belonging. Soc Educ 70, 324-345.

Hurtado S, Milem JF, Clayton-Pederson AR, Allen WR (1999). Enacting Diverse Learning Environments: Improving the Climate for Racial/Ethnic Diversity in Higher Education, Washington, DC: Jossey-Bass.

Kaplan K (2012). Postdoc or not? Nature 483, 499-500.

Lam A, de Campos A (2015). "Content to be sad" or "runaway apprentice"? The psychological contract and career agency of young scientists in the entrepreneurial university. Hum Relat 68, 811-841.

Leggon CB (2010). Diversifying science and engineering faculties: intersections of race, ethnicity, and gender. Am Behav Sci 53, 1013-1028.

Lent RW, Brown SD, Hackett G (1994). Toward a unifying social cognitive theory of career and academic interest, choice, and performance. J Vocat Behav 45, 79-122.

Lent RW, Sheu H-B, Singley D, Schmidt J, Schmidt LC, Gloster CS (2008). Longitudinal relations of self-efficacy to outcome expectations, interests, and major choice goals in engineering students. J Vocat Behav 73, 328-335.

Lizzio A, Wilson K, Simons R (2002). University students' perceptions of the learning environment and academic outcomes: implications for theory and practice. Stud High Educ 27, 27-52.

Martinez ED, Botos J, Dohoney KM, Geiman TM, Kolla SS, Olivera A, Qiu Y, Rayasam GV, Stavreva DA, Cohen-Fix O (2007). Falling off the academic bandwagon. Women are more likely to quit at the postdoc to principal investigator transition. EMBO Rep 8, 977-981.

McDowell GS, Gunsalus KT, MacKellar DC, Mazzilli SA, Pai VP, Goodwin PR, Walsh EM, Robinson-Mosher A, Bowman TA, Kraemer J, et al. (2014). Shaping the future of research: a perspective from junior scientists. F1000Res 3, 291.

National Academy of Sciences (2014). The Postdoctoral Experience Revisited, Washington, DC: National Academies Press.

National Institutes of Health (NIH) (2012). Biomedical Research Workforce Working Group Report. http://biomedicalresearchworkforce .nih.gov/background.htm (accessed 1 December 2014).

NIH (2014a). Enhancing the Diversity of the NIH-Funded Workforce. http://commonfund.nih.gov/diversity/initiatives (accessed 1 December 2014). 
NIH (2014b). RFA-RM-12-022: NIH Director's Biomedical Research Workforce Innovation Award: Broadening Experiences in Scientific Training (BEST) (DP7). http://grants.nih.gov/grants/guide/rfa -files/RFA-RM-12-022.html (accessed 15 January 2015).

National Research Council (2000). Enhancing the Postdoctoral Experience for Scientists and Engineers: A Guide for Postdoctoral Scholars, Advisers, Institutions, Funding Organizations, and Disciplinary Societies, Washington, DC: National Academies Press.

National Science Foundation (2013). Survey of Graduate Students and Postdoctorates in Science and Engineering, Fall 2012. http:// ncsesdata.nsf.gov/gradpostdoc/2012 (accessed 22 December 2014).

Polka JK, Krukenberg KA (2014). Making science a desirable career. Science 346, 1422.

Puljak L, Sharif W (2009). Postdocs' perceptions of work environment and career prospects at a US academic institution. Res Eval $18,411-415$.

Rockey SJ (2014). Women in biomedical research. National Institutes of Health Office of Extramural Research: Rock Talk http:// nexus.od.nih.gov/all/2014/08/08/women-in-biomedical-research (accessed 1 June 2015).
Sauermann H, Roach M (2012). Science PhD career preferences: levels, changes, and advisor encouragement. PLoS One 7, e36307.

Scaffidi AK, Berman JE (2011). A positive postdoctoral experience is related to quality supervision and career mentoring, collaborations, networking and a nurturing research environment. High Educ 62, 685-698.

Tabak LA, Collins FS (2011). Weaving a richer tapestry in biomedical science. Science 333, 940-941.

van Dijk D, Manor O, Carey LB (2014). Publication metrics and success on the academic job market. Curr Biol 24, R516-R517.

Weissman J (2014). The stagnating job market for young scientists. Slate. www.slate.com/articles/business/moneybox/2014/07/employmen t_rates_for_stem_ph_d_s_it_s_a_stagnant_job_market_for_young _scientists.html (accessed 15 January 2015).

Yamamoto K (2014). Time to rethink graduate and postdoc education. iBioMagazine. www.ibiology.org/ibiomagazine/issue-11/ keith-yamamoto-time-to-rethink-graduate-and-postdoc-education .html (accessed 15 February 2015).

Zelden AL, Pajares F (2000). Against the odds: self-efficacy beliefs of women in mathematical, scientific and technological careers. Am Educ Res J 37, 215-246. 